\title{
Include Me Out? The New Politics of Place and Poverty
}

\author{
Mark Kleinman
}

\section{Contents}

1. Introduction

2. London and regeneration

3. Social exclusion

4. The policy agenda

5. Conclusions

References

CASEpaper

CASE/11

August 1998
Centre for Analysis of Social Exclusion

London School of Economics

Houghton Street

London WC2A 2AE

CASE enquiries: 01719556679 


\section{Centre for Analysis of Social Exclusion}

The ESRC Research Centre for Analysis of Social Exclusion (CASE) was established in October 1997 with funding from the Economic and Social Research Council. It is located within the Suntory and Toyota International Centres for Economics and Related Disciplines (STICERD) at the London School of Economics and Political Science, and benefits from support from STICERD. It is directed by Howard Glennerster, John Hills, Kathleen Kiernan, Julian Le Grand and Anne Power.

Our Discussion Papers series is available free of charge. We also produces summaries of our research in CASEbriefs. To subscribe to the series, or for further information on the work of the Centre and our seminar series, please contact the Centre Administrator, Jane Dickson, on:

Telephone: UK+171 9556679

Fax:

UK+171 2422357

Email:

j.dickson@lse.ac.uk

Web site:

http:/ / sticerd.lse.ac.uk/case.htm

(C) Mark Kleinman

All rights reserved. Short sections of text, not to exceed two paragraphs, may be quoted without explicit permission provided that full credit, including (C) notice, is given to the source. 


\section{Editorial Note}

Mark Kleinman is Senior Lecturer in the Department of Social Policy at the London School of Economics, and an associate of CASE.

This paper is a revised version of a lecture given at the Institute of Contemporary Arts, London in March 1998. The lecture formed part of a series, titled Time, Space and Society, to mark the tenth anniversary of the Institute of Public Policy Research (IPPR).

\section{Abstract}

London is being successfully regenerated at present, yet poverty and social exclusion are increasing. The paradox is explained in part by the openness of the London economy and the lack of basic skills of a substantial minority of the population. The Government's policies for tackling social exclusion are undermined by conflating the concept of social exclusion with the discredited terminology of the "urban underclass". To be effective, policy needs to be less economically conservative, and more focused on piecemeal reforms. 


\section{Introduction}

If you look at the web-site set up by the New Millennium Experience Company (www.mx2000.co.uk) you will find, among other things, a picture and video gallery. One of the most striking pictures is a view taken from a point just east of the site of the Millennium Dome. In the foreground, a computer-generated image of the completed Dome has been seamlessly inserted onto the current construction site; in the middle distance there is the now familiar London landmark of Canary Wharf; beyond there are the meanders of the Thames which enclose in their apparently gentle loops, the heart of one of the world's few true global cities.

It is a stunning image, and brings home the historical audacity of contemporary attempts, through the Docklands investment, the Millennium site, and perhaps, the Channel Tunnel Rail Link, to reverse the centuries-old westward growth of London.

But the architecture of the Dome (or at least the architecture of the virtual Dome to which the Internet gives us access) suggests another image - that of a huge and billowing parachute which has been safely landed at the very tip of a forgotten and unloved peninsula of the Thames. I want to start from this image, because I believe it suggests an approach to urban regeneration, and to the wider issue of social exclusion, which is becoming increasingly dominant in government. This approach is fundamentally wrong, and if it continues to inform policy will seriously weaken the attempt of this Government to tackle poverty and social exclusion.

Let me set the scene. After a long period of conservative government, and government neglect of issues of poverty and inequality, an incoming government under a dynamic, charismatic young leader puts these issues at the top of the agenda. But this leadership is also concerned about re-election, and the need to carry with it the broad mass of the population, who are not poor. It wishes to get away from the 'government knows best' approach, and emphasises community participation. A broadly sympathetic commentator writes:

"There [are] three key elements to community action...It [should] operate at the ground level; community action agencies [should] be located in poor neighborhoods, not downtown office buildings. It [should] co-ordinate a wide variety of social services in a single location so that poor people wouldn't have to spend half their lives shuttling 
between the welfare office and the public housing office and the job placement office. Finally, it [should] plan its activities based on what the poor people actually [want] from government, rather than what bureaucrats in [the capital] thought they needed."

A key element in the strategy is welfare reform, and members of the government proselytise for the new approach under the slogan that welfare benefits should be "a hand up, not a handout".

This is a familiar scenario to all those who have followed the actions of New Labour in its first 10 months in office. Except that this is neither New Labour under Blair in 1998, nor even New Democrats under Clinton in 1992. It is the New Frontier under John Kennedy in 1963, and the quote above (slightly adapted) is from Nicholas Lemann's perceptive book about race and poverty in America, "The Promised Land".

It is impossible to read the sections of the book which deal with the evolution of the policy that became the 'War on Poverty' without a strong sense of déjà vu. Lemann writes:

"Most economists, and economics-oriented liberals, believed that the real cure for poverty was income redistribution, but that was not an option...because Lyndon Johnson was unalterably opposed to it...on Johnson's orders, Lester Thurow, then a junior member of the staff of the Council of Economic Advisers, was given the task of going through the Economic Report of the President removing anything that could be construed as a reference to putting cash in the hands of poor people. There had to be programs to end poverty."

It is also instructive to note how dissenters were dealt with at that time. Elizabeth Wickenden wrote to President Johnson's deputy Chief of Staff on Jan $4^{\text {th }} 1964$ :

"The problems of poverty are only in limited instances localised in character. They are for the most part widely distributed, related to economic and social factors that operate nationwide, and would require more than local action for solution."

In my view, as a two-sentence analysis, this is just about right, and equally relevant to a discussion of social exclusion in Britain in 1998, as it was to a discussion of poverty in the US in 1964. But it did not go down well then, just as it does not go down well now. Lemann writes that Wickenden received only a brief, patronising note from the deputy's deputy. 
Under the War on Poverty in the US in the 1960s, area based initiatives proliferated. A proposal to have demonstration projects in 6 or perhaps 10 cities became 250 in the first year of operation and then a thousand cities by 1967. There are echoes here too: currently in England, we have more than 500 regeneration schemes nationally supported by the Single Regeneration Budget Challenge Fund, as well as 31 City Challenge companies and several Urban Development Corporations reaching the end of their lives. On the way are Health Action Zones, Education Action Zones and Employment Action Zones.

I am not opposing area-focused programmes - quite the reverse. My own research on urban regeneration and on employability initiatives has convinced me that programmes work best when they are based on genuine partnerships, on the commitment at all levels of the private and public sector partners, and on a clear understanding of the local environment. But local initiatives cannot alone provide solutions to problems whose causes are national or even international. Local initiatives must be supported by the right kind of policies at regional and national level. There is also a limited role for the European Union, but the influence of European institutions, despite the rhetoric, is peripheral. It will remain so, until and unless we all decide we want a proper Federal Europe with a Federal government that taxes and spends.

The various Zones and other initiatives will, to a limited degree, focus resources on the worst-off areas, and this is to be welcomed. Moreover, the Prime Minister has spoken about the need to improve coordination between government departments and between agencies - he has said that "joined up problems demand joined up solutions". But they also need some joined up thinking, and this means going back to some basics and thinking hard about what regeneration and exclusion really mean. It will also mean some hard choices for the Government -that is, real hard choices, not the PR version - about which policies to pursue.

What I am going to do in this lecture is: first, look at the links between regeneration and inequality in London; secondly, examine what is meant by 'social exclusion'; and thirdly discuss the policy agenda.

\section{London and regeneration}

London is, as we all know, booming. Around the LSE where I work, new restaurants and bars open almost every week. House prices in London rose sharply last year, drawing comparisons with the boom-and-bust 1980s. London teems not only with students and tourists, but also with thousands of job seekers too. These range from young people from 
literally all over the world finding a niche in London's expanding formal and informal service economy to unemployed Parisian bankers and lawyers relocating to London who put up with the overcrowded Tube and plastic-wrapped cheese. Indeed early in 1998, more than a quarter of a million rural dwellers came to London just to enjoy a Sunday afternoon walk from Trafalgar Square to Hyde Park - a simple pleasure so many of us take for granted.

In the run-up to the Millennium, London is also being 'regenerated'. A word that includes large flagship projects such as the Dome, the new Wembley Stadium, a new bridge across the Thames, the redevelopment of the South Bank, the opening up to street life of key central London Squares, through continuing major investments in areas such as the Royal Docks, Stratford, Paddington and Kings Cross, to literally hundreds of local and community-based partnerships.

This impetus for urban revitalisation has been given another spin by the recent concern about increased urban sprawl to accommodate the projected increase in the number of households. All sorts of bodies and individuals, who previously had only marginal interest at best in urban issues, have declared themselves to be strongly in favour of 'brownfield' development. By this, they mean the re-use of contaminated, derelict and ex-industrial sites within cities for new housing, in order to stop encroachment on the countryside. But if the town cannot go to the countryside, then the countryside must come to the town, so brownfield developments are to be villages, or at least "urban villages". The West Silvertown Urban Village is already being built in the Docklands, and we are soon to have a Millennium Village on the Greenwich Peninsula next to the Dome.

We have been here before. In the 1980s, the London economy boomed. The decades-old decline in central London's employment and population was halted and even reversed. Skill shortages emerged in key industries and the infrastructure, particularly transport, groaned under the strain. But the effect on unemployment particularly in the most disadvantaged parts of the city, inner London and east London was negligible. The increased demand for labour was met not by drawing on the pool of unemployed labour in London, but rather by attracting more commuters into central London from all over the South-East.

Despite the boom, inequality and social exclusion increased in London (London Research Centre, 1996). The position of those at the bottom of the earnings ladder worsened. In 1979, the bottom $10 \%$ of male earners earned $64 \%$ of median earnings, but this had fallen to $54 \%$ by the 1990s. The number of adult residents in receipt of income support rose 
from just over 500,000 in 1989 (11\%) to almost 1 million in 1994 (17\%). Including partners and children, over 1.5 million Londoners - residents of a true global metropolis and living in supposedly the "coolest city on the planet" - rely upon Income Support to feed and clothe themselves.

In 1991, deaths in the most deprived neighbourhoods in London were some $25 \%$ higher than expected (on standardised national mortality rates) while in the most affluent areas, deaths were $20 \%$ lower than expected. Violent crime increased by 130\% between 1981 and 1993.

In 1997, the unemployment rate in London, on the ILO Labour Force Survey definition stood at $9.6 \%$ - this is higher than the North-East region, the North-West region and Northern Ireland. Only Merseyside has a higher unemployment rate. Unemployment among some groups, particularly young black men is far higher.

In short, London has a dynamic and successful economy, yet hundreds of thousands of Londoners are unemployed. The key to this paradox is the openness of the economy. London employers' demand for labour can be met by drawing on the national and international labour market at the top end; drawing on commuters in the middle skill range, while low-skill jobs are often filled by foreign workers, who now account for $30 \%$ or so of jobs in catering, cleaning and domestic services.

A recent study by the Association of London Government study found that

"there is a very weak connection between local economic performance and the incidence of unemployment, even at the Greater London level. For smaller areas within London, this is even more true; spatial variations in unemployment rates essentially reflect the residential distribution of those groups in the weakest competitive position"

(Association of London Government, 1998)

Moreover, the relative position of these workers deteriorates over time, leading to entrenched problems of social exclusion:

"There seems to be a progressive marginalisation, so long as high unemployment persists, of those groups of workers in the weakest competitive positions - who are highly concentrated in a few locations within the region."

(Association of London Government, 1998)

In other words, the core reason why unemployment in some neighbourhoods in London is much higher than the national average is that these areas contain relatively high proportions of households with 
those characteristics that are associated with unemployment. By putting the issue in this way I do not mean to imply that individuals are to blame for their own unemployment. I mean that in a competitive, open economy, those individuals that have the least competitive attributes will find it most difficult to gain access to jobs.

Research on local labour markets in London supports this view. For example, in West London, demand from employers for labour is concentrated at the level of NVQ3 and above, while the local supply shows predominance at level NVQ2 and below. Some experts believe that by 2006, the entry-level requirement for the West London labour market will be NVQ4, that is, a university degree or its vocational equivalent. This leads to the phenomenon of high-skill workers commuting into the area and excluded and unemployed local residents.

Despite nearly 24,000 unemployed people in West London, $50 \%$ of all vacancies remained unfilled at the end of the first quarter 1997. For every unfilled vacancy at the end of April 1997, there were four applicants who could not secure that job. This includes 1,600 jobs requiring minimal or no skills that remained unfilled despite 4,300 applicants. West London Training and Enterprise Council commented that
"Applicants just do not possess the required skills, experience and, more importantly, attitude...The [1997 Workforce] Survey shows that, worryingly, those most in need of education and training, i.e. those with no qualifications, are the people least likely to be considering any future education or training."

Clearly, these are issues of labour market mismatch. Many unemployed residents in London do not possess the characteristics in terms of skills, education and attitudes, which employers are looking for. I shall return later to this issue of employability. The main point I want to make here is that the solution to high unemployment in deprived areas cannot be found simply by looking at these areas alone. We must look at the connection or lack of connection between areas of concentrated poverty and the rest of the economy. Those living in poor areas are not excluded by globalisation. It would be more accurate to say they are excluded from globalisation.

\section{Social exclusion}

This used to be an obscure term associated mainly with French academic sociologists and worthy if impenetrable European Commission 
documents on Doing Good. But the concept of social exclusion has moved to centre stage in British policy-making with remarkable speed. In doing so, its lack of precise meaning has been an asset rather than a liability, much as it was in the rapid ascent of the term 'underclass' several years ago. But in trying to understand the causes of problems, and to devise effective policy, this lack of precision is more than a liability - it is catastrophic.

The government, or at least its leadership, appears to have few worries about what the precise meaning of such terms. In his speech in Southwark on 2 June 1997, just one month after the election, the Prime Minister said there was a case in terms of both morality and enlightened self-interest to "tackle what we all know exists - an underclass of people cut off from society's mainstream, without any sense of shared purpose." In another speech in December, launching the Social Exclusion Unit, he argued

"Social exclusion is about income but it is about more. It is about prospects and networks and life-chances. It's a very modern problem, and more harmful to the individual, more damaging to self-esteem for society as a whole, more likely to be passed down from generation to generation, than material poverty."

Speaking to the Fabian Society in August 1997, Peter Mandelson, the Minister without Portfolio went further:

"There are 3 million people living in the worst 1,300 housing estates expressing multiple deprivation, rising poverty, unemployment, educational failure and crime. Behind these statistics... are people who have lost hope trapped in fatalism. They are today's and tomorrow's underclass, shut out from society."

In the same speech, Mr. Mandelson stated baldly "Our vision is to end social exclusion. The task...will not be easy. But it is essential for the government's success."

The imagery drawn on by both Blair and Mandelson is that of the "urban underclass", a powerful image much represented in the media. This underclass, "shut out" or "cut off" from society is what "we all know" exists. But this is precisely where we need some joined-up thinking. In fact, as a way of understanding the set of problems that confronts us, the concept of the "underclass" is, to borrow a phrase from 
the physicists "not even wrong". As description it is inaccurate, as analysis worse than useless, and as a guide to policy positively harmful.

The term "underclass" was imported from the United States in the early 1980s. The two leading American scholars of the problems of concentrated poverty and joblessness are Christopher Jencks and William Julius Wilson. Neither of these scholars has any use for the term in the sense implied by the above quotes, i.e. a separate class of people cut off from the mainstream.

In a key article, Jencks (1991) showed that the debate about the 'urban underclass' in the U.S. conflated a number of separate policy issues. Some of these problems were getting worse - male joblessness and unwed parenthood. Some had stopped getting worse - welfare dependency and violence. Some were getting better - the numbers of high-school dropouts and reading and maths skills. Some had stopped getting better - teenage parenthood and the numbers in poverty, which fell 1940-70, but then did not change much after 1970. Few people fit the 'middle-class' or 'underclass' label exactly. Jencks argued that we do not need 'metasolutions' to a 'metaproblem', but rather piecemeal reform, changing institutions and attitudes in hundreds of small ways.

William Julius Wilson has moved away from the use of the term 'underclass', preferring instead the phrase 'ghetto poor'. Furthermore, as Wilson's detailed and painstaking research in Chicago has shown, there is no evidence that the urban poor embrace a set of moral values at odds with the wider society:

"Our research reveals that the beliefs of inner-city residents bear little resemblance to the blanket media reports asserting that values have plummeted in impoverished inner-city neighborhoods of that people in the inner city have an entirely different value system. What is so striking is that despite the overwhelming joblessness and poverty, black residents in inner-city ghetto neighborhoods actually verbally endorse, rather than undermine, the basic American values concerning individual initiative."

(Wilson, 1996: 179)

British research findings are similar. Lydia Morris, for example, interviewed three groups of married couple households in North-east England, divided into 3 groups: those where the man was long-term unemployed, those where the man was in stable employment, and those where the man was in less secure employment. She concluded: 
"there is no direct evidence in my study of a distinctive culture of the 'underclass'. There are differences of a kind which will add to the already disadvantaged position of the unemployed, but not which separate them off as having a fundamentally different style of living."

(Morris, 1993: 410)

'Underclass' as a term of analysis rightly no longer claims any intellectual respect.

Social exclusion has considerably more potential as an explanatory concept. As Atkinson (1998) argues, social exclusion can be distinguished both from poverty and from unemployment, although all three concepts are related. In seeking to discern a clearer definition of social exclusion in the current debate, Atkinson emphasises three features, which he terms relativity, agency and dynamics.

By relativity, he means that the concept implies looking not just at the circumstances of individuals but also their relationship to others: "People become excluded because of events elsewhere in society" (Atkinson, 1998: 7). Indeed, social exclusion may perhaps be thought of as a property of groups rather than individuals: "social exclusion often manifests itself in terms of communities rather than individuals, an illustration being the use by financial institutions of street postcodes for purposes of credit rating."

Secondly, the term social exclusion "implies an act, with an agent or agents". If someone is excluded, there is someone else - an individual, a group of people, an institution or a market - who does the excluding. This brings the concept of power into the discussion, although Atkinson does not develop this point.

Thirdly, exclusion is a dynamic concept: "People are excluded not just because they are currently without a job or income but because they have little prospects for the future." This aspect of the debate links both with earlier social policy concerns about the extent to which poverty or deprivation is transmitted across generations (Rutter and Madge, 1976), and also with contemporary work on the dynamics of poverty, using large-scale panel and longitudinal data (Hills, 1998; Jarvis and Jenkins, 1997a, 1997b).

However, in the current policy debate, the potential for the concept of social exclusion to improve understanding and thereby assist policy is being seriously weakened by two tendencies. First, as in the speeches quoted above, the term 'social exclusion' is used interchangeably with the discredited concept of the 'underclass'. Secondly, the term is rapidly 
becoming a cliché to cover almost any kind of social ill. There are two key strands to this discussion, which seem to me to be crucial.

Firstly, the notion of 'socially excluded' implies that there is a majority population that is included. The key social cleavage is not between social groups or economic classes, but between a comfortable majority and an excluded minority. One effect of this analysis is to minimise differences and conflict of interests in the majority population. Focusing on social exclusion is politically attractive because it avoids the difficulties associated with addressing inequalities and power relations in the wider society.

Secondly, social exclusion is defined almost entirely in the current debate by reference to exclusion from the labour market. To be socially included is to work, and to work is to be socially included. Where this leaves full-time (or even part-time) mothers is unclear, nor where it leaves the millions of full-time carers undertaking billions of pounds of unpaid work for others. Furthermore, even in relation to the formal labour market, this seems a dangerous assumption. As Atkinson (1998) says: "Unemployment may cause social exclusion, but employment does not ensure social inclusion; whether or not it does so depends on the quality of the work offered."

This raises the question of what we understand by social inclusion or social integration. The current vogue is that social inclusion has something to do with community, with networks, with belonging. Architectural fashion has come a long way from Le Corbusier's 'Unite d'Habitation' to today's urban villages. Socially excluded areas don't just need jobs and better homes - apparently they need community centres, self-help groups, voluntary organisations and community businesses. I don't quite follow the logic here, as these all seem to be things which better off areas don't have, or at least, don't have that much of. I think something important is being missed here.

In one regeneration scheme I studied, an entire 1960s council estate was being demolished, and replaced with new, more traditional housing. The existing tenants were being moved out to temporary accommodation before moving back to the new housing. Residents were consulted in great detail about the design or their new homes, and the immediate environment. To the dismay of the well-trained and community-minded architects who undertook the consultation, the tenants came up with designs that were pretty near indistinguishable from the mass products of the volume house-builders. When the architects pointed this out, they were told "that's the point. We want to be normal." On the same scheme, a budget allocation for a community centre has been placed into trust 
temporarily: the residents did not want a community centre. Normal Britain (or "socially included" Britain) doesn't have community centres people meet in pubs or in the street, at ASDA or Tesco.

Our recent research on employability confirms this pattern. In one case, it was reported that "local people did not want another training scheme. They wanted to get jobs"; while in another case study, a key factor in the success of an innovative training scheme was the fact that training was delivered in the headquarters building of a major IT firm. Schemes are credible where they have a real link to the world of work.

The more general point is that it often seems to be assumed that social order requires social cohesion. Is this in fact true? The American sociologist Mary Baumgartner studied social interaction in a suburb of New York City, chosen precisely because of its tranquillity and relative social harmony (The Moral Order of the Suburb, 1988).

She looked at the handling of interpersonal tensions in everyday life as these occur in families, neighborhoods, and public places. "The central theme is that the moral order of the suburb is the product of a distinctive social environment - one, moreover, which is becoming increasingly prevalent in the modern world."

Baumgartner's conclusions are surprising to those who would lay the blame for society's ills on the collapse of civil society and the sense of community:

"People in the suburbs live in a world characterised by nonviolence and nonconfrontation in which civility prevails and disturbances of the peace are uncommon. In this sense, suburbia is a model of social order. The order is not born, however, of conditions widely perceived to generate social harmony. It does not arise from intimacy and connectedness, but rather from some of the very things more often presumed to bring about conflict and violence - transiency, fragmentation, isolation, atomization, and indifference among people. The suburbs lack social cohesion but they are free of strife."

(Baumgartner, 1988: 134)

Baumgartner calls this "moral minimalism", and points out that it is an unusual phenomenon in cross-cultural perspective - that is, few other developed societies have it. She argues that it is the distinct patterns of social stratification and social morphology in the suburbs that account for it: 
"People in the suburbs move in and out of relationships frequently and live their lives under conditions of privacy, individuation, material independence, and freedom from authority, all the while surrounded by a wide variety of competing interests and associates."

(Baumgartner, 1988: 128)

Moral minimalism entails not only indifference in the face of potential social conflict, but a wider indifference to the fate of others: "If people in such places cannot be bothered to take action against those who offend them or to engage in conflicts, neither can they be bothered to help those in need. Positive obligations to assist others are thus also minimal where moral minimalism flourishes...If weak social ties generate weak social control, they undermine strong patterns of mutual aid as well." (ibid., p.131).

There are important differences between U.S. and Britain both in terms of urban structure, and also in terms of the degree of social, spatial and ethnic segregation. But there are enough similarities to make Baumgartner's conclusions relevant to a consideration of Britain also.

If social cohesion is thus a chimera, where does this leave social exclusion? The danger is that the emerging ideology of social inclusion will lead to the imposition of modes of behaviour on the poor, which the rest of society has rejected. This may well be acceptable to conservative ideologists. But it is (I hope) unacceptable to a Labour or even New Labour government.

\section{The policy agenda}

What is the link between urban regeneration and these issues? How does place come in? Debate about the impact of the Millennium Dome and other flagship projects often deteriorates quickly into ritualistic responses. For those engaged in the competitive business of city marketing, and for "urban boosters" generally, such mega-projects are straightforwardly beneficial. As well as the direct effects of the new spending, tourism and related spin-offs will generate jobs and economic activity that will trickle down to the whole community. Flagship projects raise 'competitiveness' and establish global identity, two sine qua non for the modern age.

On the other hand, for many community activists and professional pessimists, it is an article of faith that local needs will be ignored and benefits will be concentrated in a small number of mainly non-local hands. 
"Whatever it is, it's not for the likes of us" is a uniquely British phrase that captures a particular attitude towards change and development.

Flagship projects and major public/private investments have a key role to play in regeneration. But the linkages to wider social and economic benefits have to be carefully thought through and implemented, on a local basis. There is no single blueprint for this. Too often, the assumption is that a "training scheme" or some "community sponsorship" can be bolted onto an investment project, and benefits will automatically flow into the local economy. They won't. As countless examples have shown, jobs and revenue can simply wash into and out of an area, leaving behind very little. It doesn't have to be like this, but making it different, takes time, commitment, nerve and - as a result - money.

What we are also learning is that it is increasingly hard to draw the line between 'economic' and 'social' aspects of regeneration. Over the past twenty years policy shifted decisively towards seeking 'hard' economic end-uses as policy outcomes for regeneration spending - such as reductions in youth or long-term unemployment. But it is now becoming clear that in obtaining such outcomes, "social" factors such as family structure and individual self-esteem, and personal characteristics such as punctuality, reliability and attitude are of equal or greater importance than "economic" factors such as levels of inward investment, new floorspace provided, or even formal training qualifications. In other words, "social capital" is as important to economic development as economic capital.

While there is no blueprint for successful regeneration policy, there is much that can be done at each level of government:

- $\quad$ at local level, real partnerships involving long-term commitment by a range of groups need to be made. Real partnerships involve negotiation, innovation and risk-taking. Risk and the occasional failure should be seen as indicators of good health, not as cause for concern.

- at regional or metropolitan level, there need to be strategies to which local regeneration schemes can relate. In London, the Mayor, working through the new London Development Agency and other bodies should take a lead, and success or failure should be judged on social as well as economic criteria.

- At national level, there needs to be: first, a move away from the current obsession with quantitative performance indicators and the development of broader measures which emphasise long term 
development and sustainability; secondly a commitment by the Government to full employment and an expansionary macroeconomic regime. The limited gains that can be achieved from local and regional regeneration, particularly in terms of employment, can easily be swept away by the impact of deflationary economic policy.

What about the broader agenda on tackling social exclusion?

The first step the government should take is to link its actions on social exclusion with an attack on poverty and inequality, and in doing so, give the concept of social exclusion some credibility by separating it from the sterile and stigmatising discourse on the "underclass". My colleague David Piachaud has estimated what the effect of current government policies will be on the numbers in poverty over the next five years (Piachaud, 1998). He does this by examining the effects of demographic and economic changes and forecasting "the potential impact of New Labour policies for unemployment and welfare to work, for a minimum wage and for social security. Policies announced up to and including the Pre-Budget Statement of November $25^{\text {th }} 1997$ are analysed."

He concludes that, while the New Deal and the minimum wage will reduce poverty to some extent, these effects are far outweighed by the implications of macro-economic policy for unemployment, and the effects of failing to uprate social security benefits in line with the rise in national output. Details are shown in Table 1:

Table 1: Forecast Effect on Numbers in Poverty 1997-2002

\begin{tabular}{ll}
\hline \hline Ageing of population & Negligible \\
Growth in Lone-Parent Families & $-50,000$ to $+100,000$ \\
Level of Unemployment & $-400,000$ to $+800,000$ \\
New Deal and Welfare to Work & $-150,000$ to $-400,000$ \\
Minimum Wage ( $£ 4$ per hour) & $-300,000$ \\
Social Security Price Indexation & $+1,500,000$ \\
Overall Change & $+350,000$ to $+\mathbf{1 , 9 5 0 , 0 0 0}$ \\
\hline \hline
\end{tabular}

Source: Piachaud (1998).

This analysis remains broadly true, even taking into account the mildly redistributive effects of the March 1998 Budget. As Piachaud says, "there is nothing inevitable about the growth of poverty", and governments have real policy choices to make here.

Secondly, government has put the labour market at the centre of its programme for reducing social exclusion. Leaving aside for the moment, the issue of whether work should be seen as the only or even the main 
route to social inclusion, it is vital that employability is raised for this part of Government's programme to work.

In a recent study commissioned by BT, Anne West and I looked at the transition to work for both school-leavers and the unemployed (Kleinman, West and Sparkes 1998). We reviewed the literature and carried out case studies of employability-focused projects in England. We found that though there were excellent schemes at local level, both schoolbased and as part of wider regeneration projects, overall the national picture was not encouraging.

- There are key weaknesses in the skills that school-leavers possess, particularly 'soft' skills which are the key requirement for entrylevel jobs;

- The orientation of much of the training universe is towards providing training outputs rather than getting people into jobs;

- There is a huge culture gap between the world of work and the world of education.

We concluded that raising the employability of target groups under the New Deal will require business and government to act together both in improving the skills and attributes of those currently on benefit, and in maximising access to available entry-level jobs for those moving from benefit. The former requires a combination of improvements in basic numeracy, literacy and IT skills; personal and social skills; and job-related skills. There are serious concerns about the ability of current standard training schemes to deliver on these skills in a sustainable way to the groups targeted by New Deal. The latter requires business to look in detail at its recruitment procedures, and at the issue of stereotyping of applicants by address, age, ethnicity or gender. Increasing employability in this way will not be easy. It will require commitment, time and money on the part of both government and business. Credibility is crucial, and can easily be undermined by misguided attempts at short-term and quick-fix solutions.

Thirdly, we need policies for families and children. Family fragmentation is a major cause of poverty, inequality and social exclusion. Its direct effects in terms of reduced income are compounded by the longer term indirect effects via lowered educational achievement, low selfesteem and low aspirations. This is a major area for policy intervention, yet government is hamstrung by the continual trench warfare in the culture battle between authoritarians and libertarians. Like the Battle of the Somme, it is the foot soldiers - in this case children - who suffer the 
casualties. We have to avoid the American scenario, described by Jencks as follows:

"The 'culture wars' between liberals and conservatives have probably left American children worse off than they would be if either liberalism or conservatism were hegemonic. Because such a large minority of Americans see single motherhood as a legitimate and sometimes even the most prudent available choice, our children are unusually likely to live in households without a male breadwinner. Because an equally vociferous (and somewhat larger) minority regard single motherhood as a menace, the American government does very little to help single parents. What really puts American children at risk thus seems to be our much-vaunted diversity. What children in every country need is consensus - any kind of consensus will do - about how they should be supported. But consensus is America's scarcest commodity."

(Jencks, 1997)

Children do better, by and large, by being cared for throughout childhood by two parents who remain together, putting the needs of the family as a unit in front of individual priorities for self-fulfilment. But millions of children are growing up, and will continue to grow up in other sorts of families. Policy should start from a position of aiming to strengthen families, and to support children (not necessarily adults) whatever their family circumstances. More important than a childcare strategy is a children strategy. Mothers, including and especially lone mothers, make tremendous and self-sacrificing investments in their children. In 1995, researchers funded by the Joseph Rowntree foundation interviewed a representative sample of British children and their families. They found that:

"[a] very large percentage of mothers often or sometimes... go without clothes and shoes, holidays and entertainment in order to provide things for their children. One in twenty mothers in Britain sometimes go without food to meet the needs of their child. Lone mothers on Income Support are more likely than other mothers to go without each item and to go without more of the items. These mothers are 14 times more likely to go without food than mothers in two-parent families not on Income Support."

(Middleton, Ashworth and Braithwaite, 1997) 
Huge amounts are spent on children in Britain, but too much is on consumption and not enough on investment in children. Basic support services like health visiting and family centres as well as specialist help such as child therapy are cut back, while ever growing amounts of public resources are spent on reactive services such as the juvenile justice system. At the same time, various forms of quackery - such as the rapidly expanding 'educational software' market and the unregulated counselling industry - proliferate for the gullible middle class parent, swallowing resources that could be more usefully deployed. The problem is emphatically not one of resources: it is about the allocation of resources, and resource allocation is what government is there for.

\section{Conclusions}

Tony Blair would like the Millennium Dome to be a symbol for Britain in the $21^{\text {st }}$ Century. The Dome is rapidly becoming a symbol for New Labour, as a battleground between content and form, between the substance and the hype.

In the politics of place and poverty, I agree broadly with Christopher Jencks who wrote that he was in favour of cultural conservatism, economic egalitarianism and the virtues of piecemeal reform. Better social policy means less attention to generalities and more attention to examples.

So far, however, New Labour has shown itself to be culturally egalitarian and economically conservative. It seems impatient with piecemeal reform, and too concerned with generalities, symbols and marketing. The Government has a historic opportunity for radical reform to the politics and economics of place and poverty. Like the Dome, it has the focus of attention, and it has created an impressive superstructure. Over the next few months we will find out what is going to be put into the currently empty space. 


\section{References}

Association of London Government (1998), A Socio-Economic Assessment of London. London: Association of London Government

Atkinson, A.B. (1998), "Social Exclusion, Poverty and Unemployment" in Atkinson, A.B. and Hills, J. (eds.) Exclusion, Employment and Opportunity, CASEpaper 4, London: Centre for Analysis of Social Exclusion, London School of Economics

Baumgartner, M. (1988), The Moral Order of the Suburb. New York: Oxford University Press

Hills, J. (1998), "Does Income Mobility Mean that We Do Not Need to Worry about Poverty?" in Atkinson, A.B. and Hills, J. (eds.) Exclusion, Employment and Opportunity, CASEpaper 4, London: Centre for Analysis of Social Exclusion, London School of Economics

Jarvis, S. and Jenkins, S. (1997a), "Income dynamics in Britain: New evidence from the British Household Panel Survey" in Gregg, P. (ed.), Jobs, Wages and Poverty: Patterns of persistence and mobility in the new flexible labour market. London: Centre for Economic Performance, London School of Economics

Jarvis, S. and Jenkins, S. (1997b), "Low income dynamics in 1990s Britain", Fiscal Studies, 18 (2): 123-42

Jencks, C. (1991), "Is the American Underclass Growing?" in Jencks, C. and Peterson, P. (eds.), The Urban Underclass. Washington D.C.: Brookings Institution

Jencks, C. (1997), "The Hidden Paradox of Welfare Reform”, The American Prospect, 32: 33-40

Kleinman, M., West, A. and Sparkes, J. (1998), Investing in Employability: The Roles of Business and Government in the Transition to Work. London: London School of Economics

Lemann, N. (1991), The Promised Land. London: Macmillan

London Research Centre (1996), Mapping Poverty and Social Exclusion in London London: London Research Centre

Middleton, S., Ashworth, K. and Braithwaite, I. (1997), Small Fortunes: Spending on children, childhood poverty and parental sacrifice. York: Joseph Rowntree Foundation

Morris, L.D. (1993), "Is there a British underclass?", International Journal of Urban and Regional Research, 17 (3): 404-412

Piachaud, D. (1998), “The Prospects for Poverty”, New Economy, March 
Rutter, M. and Madge, N. (1976), Cycles of Disadvantage. London: Heinemann

Wilson, W.J. (1996), When Work Disappears. New York: Knopf 